- Original Article

\title{
Association between Near Work Time and Depression among Workers in South Korea
}

\author{
Na Rae Jeong ${ }^{1}$, Seung Hun Lee ${ }^{1, *}$, Yun Jin Kim ${ }^{1,2}$, Jeong Gyu Lee ${ }^{1,2}$, Yu Hyeon Yi ${ }^{1,2}$, Yougn Jin Tak ${ }^{1,2}$, Hye Rim Hwang ${ }^{1}$, \\ Gyu Lee Kim ${ }^{1}$, Sang Yeoub Lee ${ }^{2,3}$, Young Hye Cho ${ }^{2,3}$, Eun Ju Park ${ }^{3}$, Young In Lee ${ }^{3}$, Jung In Choi ${ }^{3}$ \\ 'Department of Family Medicine, Pusan National University Hospital, Busan, Korea \\ ${ }^{2}$ Pusan National University School of Medicine, Yangsan, Korea \\ ${ }^{3}$ Department of Family Medicine, Pusan National University Yangsan Hospital, Yangsan, Korea
}

Background: The aim of this study was to evaluate the association between near work time and depression.

Methods: Data of 1,551 workers aged 19-49 years from the sixth Korea National Health and Nutrition Examination Survey were examined. The Patient Health Questionaire-9 scores were used to screen for depression. Participants who scored a total of 10 or above, which is suggestive of the presence of depression, were classified as the depression group; the rest were classified as normal. The correlation between daily near work time and depression was analyzed using multivariate logistic analysis after adjusting for other sociodemographic and health behavior-related variables.

Results: Multivariate logistic analysis found that workers with 3 or more hours of near work were more likely to report depression compared to the reference group who had 2 or fewer hours per day of near work (adjusted odds ratio, 2.471; 95\% confidence interval, 1.062-5.747).

Conclusion: Longer near work time was associated with depression among South Korea's workers. Therefore, it is necessary to reduce near work time to prevent depression.

Keywords: Near Work Time; Depression; Work; Korea

Received: September 9, 2020, Revised: November 6, 2020, Accepted: November 16, 2020

*Corresponding Author: Seung Hun Lee https://orcid.org/0000-0002-0976-8708

Tel: +82-51-240-7834, Fax: +82-51-240-7843, E-mail: drjim@pusan.ac.kr 


\section{INTRODUCTION}

Depression is one of the most widespread mental disorders with a high prevalence rate among workers as well as the general public. Workers suffering from depression experience individual distress, which lowers their quality of life. ${ }^{1)}$ In addition, it is directly related to economic loss at the corporate and national levels due to reduced productivity. ${ }^{2)}$ Although there is no clear cause of workers' depression, there are several studies assessing the risk factors leading to its development. ${ }^{3)}$ Long working hours is a major risk factor, especially in South Korea, which is one of the countries with the longest working hours among the Organization for Economic Cooperation and Development countries.

Many previous studies have reported a relationship between long working hours and health problems such as stroke, coronary heart disease, sleep disorders, stress, and depression. ${ }^{4,5)}$ However, certain studies have suggested that long working hours may not have a direct relationship with psychological health. ${ }^{6,7)}$ It is imperative to examine the actual workload such as work type and conditions, since many previous studies have considered long working hours as a risk factor for psychological health problems. ${ }^{7)}$

Near work refers to activities performed at short viewing distances, such as using visual media or reading. With the development and dissemination of various visual media such as computers, smartphones, and tablets, the exposure time to visual media has increased. Consequently, near work time has increased significantly in both work and everyday life. However, an increase in near work time may lead to health issues such as eye problems, including dry eye syndrome, asthenopia, myopia, and musculoskeletal problems, including neck and shoulder discomfort. ${ }^{8,9)}$ In addition, a study on the association between near work and mental health reported that workers with greater near work time are at risk for high perceived stress. ${ }^{10)}$ Stress can cause physical problems such as diabetes mellitus, hypertension, and cardiovascular diseases, as well as mental problems such as cognitive disorders and depression. Furthermore, work stress is a risk factor for the development of depressive symptoms and appears to precipitate diagnosable depression. ${ }^{11-13)}$ However, no studies have reported on the direct correlation between near work time and depression.

Therefore, the purpose of this study was to investigate the cross-sectional association between near work time and depression among South Korea's workers.

\section{METHODS}

\section{Study Population}

This study used data from the 2014 Korea National Health and Nutrition Examination Survey (KNHANES) conducted by the Korea Centers for Disease Control (KCDC; currently Korea Disease Control and Prevention Agency). The Patient Health Questionaire-9 (PHQ-9) score was surveyed in 2014. Of the 7,559 participants, 1,551 workers aged 19-49 years were selected. This is because near work time has been in- vestigated only for participants in that age range. The survey protocols for KNHANES VI were approved by the Institutional Review Board of the KCDC, and informed consent was obtained from all participants.

\section{Variables and Measurements}

\section{1) Assessment of near work time}

In the KNHANES, the participants were asked, "How many hours per day on average did you spend on near work (e.g., computer work or reading) in the past year?" They were provided with four response options: (1) less than 1 hour, (2) 1-2 hours, (3) 3 hours, and (4) 4 hours or more. In a previous study on the relationship between near work time and stress perception, the stress perception was significantly higher in the group that worked for 3 hours or more. ${ }^{10)}$ Based on this, we divided the participants into two groups: (1) those doing near work for less than 2 hours, and (2) those doing near work for 3 hours or more.

\section{2) Assessment of depression}

Depression was assessed using the PHQ-9. The PHQ-9 is a nine-item questionnaire designed to screen for depression in primary care and other medical settings. The standard cut-off score for screening to identify possible major depression was 10 or above (maximum score=27). ${ }^{14)}$

\section{3) Socioeconomic and health behavior variables}

We included sociodemographic factors (sex, age, education level, marital status, and household income) and health behaviors (body mass index [BMI], smoking, and alcohol use) that may affect depression as confounding variables. In addition, occupational factors (occupation, shift work, employment type, and working hours) were included as confounding variables related to work. Age groups were 19-29 years, 30-39 years, and 40-49 years. Education level was divided into two groups: those with an education level of high school graduate or less, and those with a college degree or above. Participants' marital status was classified as married or unmarried. Based on the income data of the sample group, household income level was categorized into four groups: low, middle-low, middle-high, and high. The degree of obesity was divided into three categories: low (BMI $<23.0 \mathrm{~kg} / \mathrm{m}^{2}$ ), normal (BMI 23.0-24.9 kg/m²), and obese (BMI $\geq 25.0 \mathrm{~kg} / \mathrm{m}^{2}$ ). Smoking status was classified into current smokers, ex-smokers, and neversmokers. Alcohol consumption status was categorized into two groups: those who consumed alcohol and those who never consumed alcohol. Occupation was divided into three groups (white collar, service, blue collar) based on the Korean Standard Classification of Occupation. ${ }^{15)}$ The workers were divided into two groups: those who reported their work schedule as fixed day work were classified as day workers, and the others were classified as shift workers. Employment types were classified as regular or non-regular. Finally, based on the working hours, four groups were formed: (1) < 40 hours, (2) 40-49 hours, (3) 50-59 hours, and (4) $\geq 60$ hours. 


\section{Statistical Analysis}

We conducted chi-square tests ( $\chi^{2}$ tests) and logistic regression analyses to compare the characteristics of participants according to near work time. Odds ratios (ORs) and 95\% confidence intervals (95\% CIs) for depression were estimated using multivariate logistic analyses. Model A was adjusted for sex and age. Model B was adjusted for sex, age, socioeconomic factors (household income, education level, and

Table 1. General characteristics of the study participants

\begin{tabular}{|c|c|c|c|}
\hline \multirow{2}{*}{ Characteristic } & \multicolumn{2}{|c|}{ Near work time/d } & \multirow{2}{*}{ P-value } \\
\hline & $<2 \mathrm{~h}$ & $\geq 3 \mathrm{~h}$ & \\
\hline Sex & & & 0.534 \\
\hline Male & 279 (57.8) & 501 (59.5) & \\
\hline Female & 307 (42.2) & $464(40.5)$ & \\
\hline Age (y) & & & $<0.001$ \\
\hline $19-29$ & $72(17.2)$ & 242 (31.7) & \\
\hline 30-39 & 196 (29.1) & 407 (38.1) & \\
\hline $40-49$ & 318 (53.8) & 316 (30.2) & \\
\hline Education level & & & $<0.001$ \\
\hline High school or less & 366 (65.8) & $317(35.9)$ & \\
\hline College or above & 219 (34.2) & $648(64.1)$ & \\
\hline Marital status & & & $<0.001$ \\
\hline Yes & 487 (80.4) & $616(58.6)$ & \\
\hline No & 99 (19.6) & 349 (41.4) & \\
\hline Household income & & & 0.007 \\
\hline Low & $36(5.9)$ & $41(4.7)$ & \\
\hline Middle-low & $154(27.0)$ & 173 (19.6) & \\
\hline Middle-high & $219(36.0)$ & $351(35.3)$ & \\
\hline High & 175 (31.1) & 399 (40.4) & \\
\hline Body mass index & & & 0.688 \\
\hline Low & $32(4.4)$ & $53(5.5)$ & \\
\hline Normal & 374 (65.3) & $616(64.0)$ & \\
\hline Obese & $171(30.3)$ & $280(30.5)$ & \\
\hline Smoking & & & 0.188 \\
\hline Current-smoker & 188 (37.1) & 281 (32.3) & \\
\hline Ex-smoker & 76 (15.6) & $172(18.7)$ & \\
\hline Non-smoker & $319(47.3)$ & $509(49.0)$ & \\
\hline Alcohol use & & & 0.426 \\
\hline Drinking & $387(70.1)$ & $677(72.1)$ & \\
\hline Never & $196(29.9)$ & $285(27.9)$ & \\
\hline Occupation & & & $<0.001$ \\
\hline White collar & $181(27.4)$ & $665(66.2)$ & \\
\hline Service & 168 (29.1) & 176 (19.3) & \\
\hline Blue collar & 237 (43.5) & $124(14.5)$ & \\
\hline Shift work & & & 0.607 \\
\hline Yes & $31(5.3)$ & $44(4.7)$ & \\
\hline No & $555(94.7)$ & $918(95.5)$ & \\
\hline Employment type & & & 0.014 \\
\hline Regular & $162(41.0)$ & $422(50.5)$ & \\
\hline Non-regular & $233(59.0)$ & $365(49.5)$ & \\
\hline Working hours/wk & & & $<0.001$ \\
\hline$<40$ & $214(34.5)$ & $278(28.2)$ & \\
\hline $40-49$ & $165(28.6)$ & $422(43.5)$ & \\
\hline $50-59$ & $106(18.9)$ & $163(17.1)$ & \\
\hline$\geq 60$ & $101(18.0)$ & $102(11.2)$ & \\
\hline
\end{tabular}

Values are presented as number of persons (weighted \%). P-values for the differences in variables among the two groups for daily near work time were obtained by chisquare test for categorical variables or by analysis of variance for numerical variables. marital status), and health behavior factors (BMI, smoking, and alcohol use). Model C was adjusted for sex, age, socioeconomic factors, health behavior factors, and occupational factors (occupation, working hours, shift work, and employment type). All statistical analyses were performed using IBM SPSS ver. 25.0 (IBM Corp., Armonk, NY, USA). Statistical significance was set at $\mathrm{P}<0.05$.

\section{RESULTS}

The baseline characteristics of the study participants according to the near work time are presented in Table 1. In total, 965 out of 1,551 participants reported spending 3 hours or more on near work. In the univariate analyses, distributions of age, education level, marital status, household income, occupation, employment type, and weekly working hours indicated significant differences between the near work times of 3 hours or more and 2 hours or less group. Workers with daily near work times of more than 3 hours were found to be younger, more educated, and had higher incomes. Additionally, unmarried workers, white-collar workers, and workers with fewer weekly working hours were more likely to report higher daily near work time. However, the distributions by sex, BMI, smoking, alcohol use, and shift work did not show significant differences between the two groups.

Table 2 illustrates the prevalence of depression according to daily near work time. The 3 hours or more daily near work time group (6.0\%) had higher PHQ-9 scores compared to the 2 hours or less daily near work time group (3.5\%). Therefore, the 3 hours or more daily near work time group tended to have more workers with a PHQ-9 score of 10 or more. However, no statistically significant differences were observed between the two groups $(\mathrm{P}=0.067)$.

Table 3 indicates the results of the multivariate logistic regression analysis of the association between daily near work time and depression according to the PHQ-9 score. Participants with daily near work times of 3 hours or more observed a significantly higher OR than those with daily near work times of 2 hours or less after adjustment (OR, 2.471; 95\% CI, 1.062-5.747).

\section{DISCUSSION}

This study investigated the relationship between daily near work time and depression among Korean workers. The results indicated that the

Table 2. The PHQ-9 score according to the daily near work time

\begin{tabular}{ccc}
\hline \multirow{2}{*}{ PHQ-9 score } & \multicolumn{2}{c}{ Near work time/d } \\
\cline { 2 - 3 } & $<2 \mathrm{~h}$ & $\geq 3 \mathrm{~h}$ \\
\hline $0-9$ & $567(96.5)$ & $901(94.0)$ \\
$\geq 10$ & $18(3.5)$ & $64(6.0)$ \\
\hline
\end{tabular}

Values are presented as number of persons (weighted \%). P-values for the differences in variables among the two groups for daily near work time were obtained by chi-square test for categorical variables or by analysis of variance for numerical variables.

PHQ-9, Patient Health Questionaire-9. 
Table 3. Odds ratio (95\% confidence intervals) of depression according to daily near work time

\begin{tabular}{ccccc}
\hline \multirow{2}{*}{ Near work time/d } & Unadjusted & \multicolumn{3}{c}{ Adjusted } \\
\cline { 3 - 5 } & & Model A & Model B & Model C \\
\hline $2 \mathrm{~h}$ & 1 (Reference) & 1 (Reference) & 1 (Reference) & 1 (Reference) \\
$\geq 3 \mathrm{~h}$ & $1.766(0.950-3.282)$ & $1.426(0.750-2.711)$ & $2.005(1.015-3.959)$ & $2.471(1.062-5.747)$ \\
P-value & 0.072 & 0.278 & 0.045 & 0.036 \\
\hline
\end{tabular}

Adjusted odds ratio from multivariate logistic regression analysis. Model A: adjusted for sex and age; model B: adjusted for sex, age, education level, marital status, household income, BMl, smoking, and alcohol use; and model C: adjusted for sex, age, education level, marital status, household income, BMl, smoking, alcohol use, occupation, working hours, shift work, and employment type.

BMl, body mass index.

workers who engaged in 3 or more hours of daily near work had higher scores on the PHQ-9, and a significantly higher prevalence of depression was observed in this group compared to the 2 or fewer hours of daily near work time group (OR, 2.471; 95\% CI, 1.062-5.747). Therefore, it can be inferred that near work time is associated with depression, independent of working hours.

Several previous studies have reported an association between long working hours and depression in workers. ${ }^{16,17)}$ However, few studies have reported a relationship between near work and mental health, including depression. Moreover, the causes associated with near work time and depression have not been clearly identified. ${ }^{6)}$ Some studies have suggested the importance of investigating the type or condition of work that causes greater mental load., ${ }^{7,18}$ The job demands-resources model may be a plausible explanation for the link between near work and mental health. ${ }^{19,20)}$ According to the job demand-control model of Karasek et al., ${ }^{21)}$ workers with high job demands and low job control may be at an increased risk with respect to the various aspects of their mental as well as physical health.

A visual display terminal (VDT) is a piece of equipment with a screen on which information can be displayed, such as computers, smartphones, and tablets. The long-term use of these devices can cause several problems such as VDT syndrome. ${ }^{22)}$ The increased use of VDT during near work requires concentration that can cause stress and mental strain, in addition to ophthalmic symptoms and musculoskeletal problems. ${ }^{23)}$ The use of VDT devices has become an essential part of the modern lifestyle, and the usage time of VDT has been gradually increasing. Accordingly, near work time is expected to continue to increase in the future. Some characteristics of near work, such as inappropriate posture (e.g., awkward body posture, using keyboard or mouse), high visual demand (e.g., reading from a computer screen or book form close proximity), and mental concentration, are regarded as job demand factors in the job demand-control model. ${ }^{9,24)}$ Consequently, near work may warrant increased job demands and job strain. Furthermore, physical problems such as eye and musculoskeletal discomfort itself can have adverse effects on mental health, including the development of depression or depressive symptoms. ${ }^{25-27)}$

This study has numerous comparative advantages; it is a large-scale study with a sample representative of the Korean population. Additionally, this is the first study to examine the relationship between near work time and depression among Korean workers. However, this study has certain limitations. First, as the study is cross-sectional in design, we cannot assess whether the association between near work time and depression is causal. Second, despite the usefulness of the PHQ-9 as a screening tool, it cannot be used as a stand-alone diagnostic test. Therefore, further research focusing on the clinical diagnosis of depression is required. Third, we divided the subjects into two groups according to their near work time. However, the number of subjects in the two groups was significantly different and because of the division into two groups, various statistical analyses, including correlation analysis, could not be performed. Finally, the distributions of occupational factors showed significant differences between the two groups. The group with 3 hours or more of daily near work time tended to have higher income, shorter working hours, higher rate of regular work, and lower rate of shift work. As a result of cross-tabulation analysis of occupational factors and PHQ-9 score, the group with higher PHQ-9 scores tended to have lower income, longer working hours, lower rate of regular work, and higher rate of shift work. Consequently, there would not have been any significant differences before correction for the relevant factors.

In conclusion, this study indicated that a longer near work time was associated with the prevalence of depression in Korean workers. Further investigation is necessary to explore methods to prevent depression in workers engaged in near work.

\section{CONFLICT OF INTEREST}

No potential conflict of interest relevant to this article was reported.

\section{ORCID}

Na Rae Jeong: https://orcid.org/0000-0001-8333-1814 Seung Hun Lee: https://orcid.org/0000-0002-0976-8708 Yun Jin Kim: https://orcid.org/0000-0002-0204-3253 Jeong Gyu Lee: https://orcid.org/0000-0001-7160-0714 Yu Hyeon Yi: https://orcid.org/0000-0002-1786-2737 Yougn Jin Tak: https://orcid.org/0000-0002-4645-5866 Hye Rim Hwang: https://orcid.org/0000-0001-7658-3749 Gyu Lee Kim: https://orcid.org/0000-0003-2825-0629 Sang Yeoub Lee: https://orcid.org/0000-0002-3585-9910 Young Hye Cho: https://orcid.org/0000-0003-2176-6227 
Eun Ju Park: https://orcid.org/0000-0003-2415-8243

Young In Lee: https://orcid.org/0000-0003-0141-7484

Jung In Choi: https://orcid.org/0000-0003-3832-3393

\section{REFERENCES}

1. Kim W, Hwang TY, Ham BJ, Lee JS, Choi BH, Kim SJ, et al. The impact of major depressive disorder on productivity in workers: a preliminary study using WHO-HPQ(Health and Work Performance Questionnaire). J Korean Neuropsychiatr Assoc 2007;46:587-95.

2. Stewart WF, Ricci JA, Chee E, Hahn SR, Morganstein D. Cost of lost productive work time among US workers with depression. JAMA 2003; 289:3135-44.

3. Harris T. Recent developments in understanding the psychosocial aspects of depression. Br Med Bull 2001;57:17-32.

4. Shields M. Long working hours and health. Health Rep 1999;11:33-48.

5. Nagashima S, Suwazono Y, Okubo Y, Uetani M, Kobayashi E, Kido T, et al. Working hours and mental and physical fatigue in Japanese workers. Occup Med (Lond) 2007;57:449-52.

6. Sato Y, Miyake H, Theriault G. Overtime work and stress response in a group of Japanese workers. Occup Med (Lond) 2009;59:14-9.

7. Hobson J, Beach JR. An investigation of the relationship between psychological health and workload among managers. Occup Med (Lond) 2000;50:518-22.

8. Owens DA, Wolf-Kelly K. Near work, visual fatigue, and variations of oculomotor tonus. Invest Ophthalmol Vis Sci 1987;28:743-9.

9. Zetterberg C, Forsman M, Richter HO. Neck/shoulder discomfort due to visually demanding experimental near work is influenced by previous neck pain, task duration, astigmatism, internal eye discomfort and accommodation. PLoS One 2017;12:e0182439.

10. Jeong I, Cho YS, Lee KJ, Park JB. Impact of near work on perceived stress according to working hours: the Korea National Health and Nutrition Examination Survey VI (2013-2015). PLoS One 2018;13:e0204360.

11. van Praag HM. Can stress cause depression? Prog Neuropsychopharmacol Biol Psychiatry 2004;28:891-907.

12. Clays E, De Bacquer D, Leynen F, Kornitzer M, Kittel F, De Backer G. Job stress and depression symptoms in middle-aged workers: prospective results from the Belstress study. Scand J Work Environ Health 2007;33:252-9.

13. Melchior M, Caspi A, Milne BJ, Danese A, Poulton R, Moffitt TE. Work stress precipitates depression and anxiety in young, working women and men. Psychol Med 2007;37:1119-29.

14. Levis B, Benedetti A, Thombs BD; DEPRESsion Screening Data (DEPRESSD) Collaboration. Accuracy of Patient Health Questionnaire-9 (PHQ-9) for screening to detect major depression: individual partici- pant data meta-analysis. BMJ 2019;365:11476.

15. Kwon K, Park JB, Lee KJ, Cho YS. Association between employment status and self-rated health: Korean working conditions survey. Ann Occup Environ Med 2016;28:43.

16. Ogawa R, Seo E, Maeno T, Ito M, Sanuki M, Maeno T. The relationship between long working hours and depression among first-year residents in Japan. BMC Med Educ 2018;18:50.

17. Yoon Y, Ryu J, Kim H, Kang CW, Jung-Choi K. Working hours and depressive symptoms: the role of job stress factors. Ann Occup Environ Med 2018;30:46.

18. Amagasa T, Nakayama T. Relationship between long working hours and depression: a 3-year longitudinal study of clerical workers. J Occup Environ Med 2013;55:863-72.

19. Schaufeli WB, Taris TW. A critical review of the job demands-resources model: Implications for improving work and health. In: Bauer GF, Hammig O, editors. Bridging occupational, organizational and public health: a transdisciplinary approach. Dordrecht: Springer; 2014. p. 4368.

20. Sanne B, Mykletun A, Dahl AA, Moen BE, Tell GS. Testing the Job Demand-Control-Support model with anxiety and depression as outcomes: the Hordaland Health Study. Occup Med (Lond) 2005;55:46373.

21. Karasek R, Brisson C, Kawakami N, Houtman I, Bongers P, Amick B. The Job Content Questionnaire (JCQ): an instrument for internationally comparative assessments of psychosocial job characteristics. J Occup Health Psychol 1998;3:322-55.

22. Parihar JK, Jain VK, Chaturvedi P, Kaushik J, Jain G, Parihar AK. Computer and visual display terminals (VDT) vision syndrome (CVDTS). Med J Armed Forces India 2016;72:270-6.

23. Smith MJ. Psychosocial aspects of working with video display terminals (VDTs) and employee physical and mental health. Ergonomics 1997;40:1002-15.

24. Ranasinghe P, Wathurapatha WS, Perera YS, Lamabadusuriya DA, Kulatunga S, Jayawardana N, et al. Computer vision syndrome among computer office workers in a developing country: an evaluation of prevalence and risk factors. BMC Res Notes 2016;9:150.

25. Nordlund A, Ekberg K. Self reported musculoskeletal symptoms in the neck/shoulders and/or arms and general health (SF-36): eight year follow up of a case-control study. Occup Environ Med 2004;61:e11.

26. Goodell S, Druss BG, Walker ER, Mat M. Mental disorders and medical comorbidity. Princeton (NJ): Robert Wood Johnson Foundation; 2011.

27. Wan KH, Chen LJ, Young AL. Depression and anxiety in dry eye disease: a systematic review and meta-analysis. Eye (Lond) 2016;30:155867. 